\title{
Stem Cells, Scaffolds and Gene Therapy for Periodontal Engineering
}

\author{
Miguel Padial-Molina • Hector F. Rios
}

Published online: 21 December 2013

(C) Springer International Publishing AG 2013

\begin{abstract}
The periodontium is continually exposed to a variety of challenges. Over the past decade, preclinical and clinical research has highlighted the complex modulatory role of the periodontal ligament (PDL) as a mediator of tissue repair and homeostasis. Experiments carried out in both human and animal models have highlighted the importance of the PDL as a protective structure. The unique properties of PDL cells endow this tissue with functional attributes that are not replicated by other biological systems. Furthermore, distinct PDL matricellular properties favor a synchronized molecular response to environmental challenges that supports normal dental and alveolar adaptation. Today, the mechanism by which periodontal integrity is restored and maintained is the focus of novel and innovative research. The ability to decipher the molecular mechanisms that support periodontal homeostasis, together with emerging science in biomaterials and stem cell biology, represents a unique opportunity to enhance the predictability of current regenerative surgical approaches and to develop novel treatment strategies for periodontal tissue engineering. This review will focus on the most recent available information concerning cells, gene delivery, and new scaffold technologies that are relevant in periodontal regeneration.
\end{abstract}

Keywords Periodontal ligament · Periodontal regeneration · Periodontal engineering $\cdot$ Tissue engineering $\cdot$ Stem cells

\author{
M. Padial-Molina $\cdot$ H. F. Rios $(\triangle)$ \\ Department of Periodontics and Oral Medicine, School of Dentistry, \\ University of Michigan, 1011 North University Ave, Office 3349, \\ Ann Arbor, MI 48109-1078, USA \\ e-mail: hrios@umich.edu \\ M. Padial-Molina \\ Research Group CTS\#583, University of Granada - Junta de \\ Andalucia, Granada, Spain
}

\section{Introduction}

The tooth-supporting apparatus is composed of the alveolar bone, the periodontal ligament (PDL), the cementum, and the gingiva. The periodontium is a highly specialized, adaptive, and dynamic tissue able to sustain different microbiological, inflammatory, and mechanical challenges through a number of complex molecular events [1]. Alterations of this equilibrium in the form of different periodontal diseases affect a significant percentage of the adult population $[2,3]$.

Periodontal regeneration has long been the ultimate goal in periodontal therapy [4]. However, treating and re-establishing the diseased periodontium's original structure, properties, and function constitute a significant challenge [5]. Different approaches have been proposed, but the amount of regenerated tissue is oftentimes limited and difficult to predict. By definition, periodontal regeneration implies the regeneration of the cementum, periodontal ligament, alveolar bone in a specific temporal sequence and spatial distribution is based on a number of essential factors (Fig. 1) [6-9].

Although the exact cellular and molecular events are still not clear, we know that specific cells must first migrate to the healing area and proliferate to provide the machinery needed for the new tissue to grow and differentiate. This process is mediated and coordinated by soluble factors, many cell types, extracellular matrix (ECM), and matricellular proteins. Ideally, scaffolds will provide a three-dimensional template structure to support and facilitate these processes. Angiogenic signals and new vascular networks provide the nutritional base for tissue growth and homeostasis, after which normal mechanical stimuli will increase to promote an organized ECM synthesis as well as cementum and bone formation and maturation. Once those structures are established, PDL fibers become organized and connect the tooth to the alveolar bone. Finally, because of the microbial load at the periodontal 


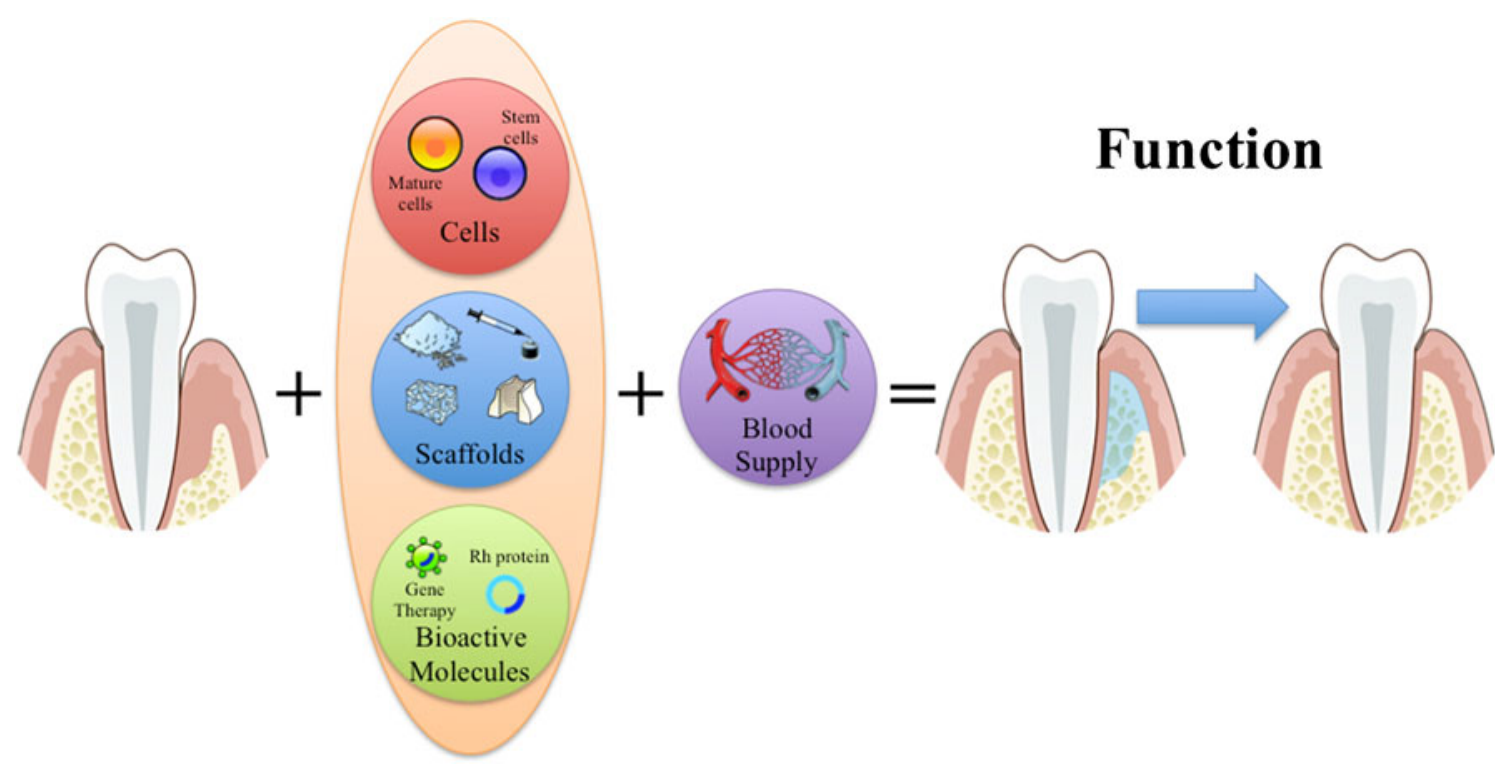

Fig. 1 Schematic illustration of principles and requirements for periodontal engineering

area, strategies to control infection and host response are required to optimize periodontal regeneration [8-10].

This paper focuses on key concepts and the most recently published information in periodontal engineering (20122013) concerning early-stage cell and gene delivery by new scaffold technologies. The discussion focuses primarily on three important aspects: 1) cell-based therapy, 2) scaffold fabrication technologies, and 3) gene therapy in periodontal engineering.

\section{Cells for Periodontal Regeneration}

Generally, cell therapy involves the transfer of new cells into a tissue to treat diseases or disorders. In regenerative medicine, cells are used to improve the regeneration process by promoting new tissue growth and differentiation [11]. They can be delivered as either promoters of multiple cell types needed in the regeneration process or as carriers to deliver different types of molecules, either directly or by gene therapy [12]. In the context of periodontal regeneration, cells seeded into periodontal defects should be easy to harvest, nonimmunogenic, and highly proliferative, and should have the ability to differentiate into various types of cells comprising periodontal tissue [13].

Different types of cells - either mature or stem cells - from both extraoral and intraoral origins have been proposed for periodontal regeneration (Table 1, adapted from [9]). During the last year, important advances have occurred in terms of new strategies to obtain these cells as well as a description of some special properties of particular interest in periodontal regeneration. This includes not only ease of access to the cells, but also initial in vivo applications that demonstrate very promising results. In that context, it is very interesting that the gingiva contains mesenchymal stem cells [GMSC) [14-19]. These cells are both mesoderm- and neural crestderived, the latter showing an increased capacity to differentiate to neural cells and chondrocytes, as well as to modulate immune cells, when compared to the other [20]. This is of special relevance since neural crest cells, as a transient, migratory, multipotent cell population, participate in the embryonic development of most dental tissues, including the gingiva, dental follicle, periodontal ligament, and alveolar bone, which are, in fact, sources of adult stem cells as well [21]. Mesenchymal stem cells have been also generated from human foreskin iPSC (induced pluripotent stem cells). These cells exhibit the capacity to regenerate periodontal tissues in a

Table 1 Types and uses of cells in periodontal regeneration (9)

\begin{tabular}{cll}
\hline Cell type & Origin & Defect type \\
\hline $\begin{array}{c}\text { Bone marrow stromal } \\
\text { cells }\end{array}$ & Autograft & Class III defects \\
& & $\begin{array}{l}\text { Periodontal fenestration } \\
\text { Osteotomy }\end{array}$ \\
Adipose stromal cells & Autograft & Periodontal palatal defects \\
$\begin{array}{c}\text { Periodontal ligament } \\
\text { cells }\end{array}$ & Autograft & Class II defects \\
& & Periodontal fenestration \\
Periodontal ligament & Allograft & Ectopic \\
stem cells & & Periodontal fenestration \\
& Autograft & Periodontal defects \\
Cementoblasts & Allograft & Ectopic \\
& & Periodontal fenestration \\
Dental follicle cells & Allograft & Ectopic \\
& & Periodontal fenestration \\
\hline
\end{tabular}


rat periodontal defect model $[22 \cdot \bullet]$. Other studies have confirmed the possibility of obtaining mesenchymal stem cells from alveolar bone marrow by slow minimally-irrigated osteotomy [23] or Bichat's fat pad [24].

More and more reports are showing the utility of periodontal ligament stem cells (PDL-SC) for periodontal regeneration $[25,26]$. These cells can be effectively isolated from the PDL and are capable of forming cementum and periodontal ligament tissues upon in vivo transplantation, as described almost a decade ago with human cells transplanted into a mouse model [27]. Such potential has been confirmed recently in a dog model, which could be used as another periodontal regeneration large-animal model [28].

The regenerative potential of PDL-SC has classically been assessed in acute rat fenestration models, where transplanted cells are carried by a collagen sponge [29]. Other approaches include chronic class II/III defects (created sometime prior to or concurrently with the regenerative procedure). These studies are usually performed in dogs. Within the last year, a report has confirmed no superiority in class II periodontal regeneration when comparing autogenous cortical bone (ACB), ACB + PRP (platelet rich plasma), or a combination of PRP + MSCs [30]. However, the lack of a MSCs + ACB + PRP group in this particular study skews the comparison. In other cases, the addition of PDL cells makes the regeneration process more effective, especially in combination with collagen sponges and collagen membranes in class III defects [31].

More recently, efforts in periodontal regeneration have begun to utilize cell sheet engineering. The principle of cell sheet engineering is based on the capacity of cells to attach and proliferate on a temperature-responsive polymer surface (usually poly(N-isopropylacrylamide) or PIPAAm). When the cell sheet has grown, cells with extracellular matrix proteins spontaneously detach from the culture dishes by lowering the temperature [32]. This approach is even being used in a clinical study with autologous PDL cells (http://upload. umin.ac.jp/cgi-open-bin/ctr/ctr.cgi?function=brows\&action= brows \& type $=$ summary \& recptno $=$ R000005979\&language $=$ E). New developments include the possibility of configuring multilayered cell sheets that could carry not only different layers of cells but also abundant extracellular matrix, which would eliminate the adverse effect of cell carriers. The approach was recently tested in a rodent animal model and showed a clear superiority over monolayer cell design [33••].

Mesenchymal stem cells derived from the PDL have been studied more extensively, although it is important to note that some reports are promoting the use of other intraoral sources such as the gingiva. While the potential to differentiate into multiple cell lineages and generate new bone ectopically is more effectively achieved using PDLSCs, some authors highlight drawbacks such as limited cell availability and reduced clinical applicability (sacrifice of a tooth to obtain stem/progenitor cells from their dental pulp or periodontal ligament) [34, 35]. Gingival-derived stem cells have been effectively applied in a recent miniature pig periodontal regeneration study [35]. The combination of autologous gingival-derived stem cells loaded in a scaffold showed better regeneration outcomes (higher changes in clinical attachment level, probing depth, gingival recession, histological attachment level, and lower junctional epithelium length and connective tissue adhesion) compared with unloaded scaffolds and negative controls. Interestingly, this study initially induced periodontal defects over a period of 4 weeks, which indicates some advantage over an acute intrasurgically created defect.

\section{Delivery of Cells for Periodontal Engineering}

There are various cell delivery methods in periodontal engineering applications (Table 2, adapted from [36]). In general, scaffolds are used in tissue regeneration to provide and maintain the necessary space for the cells to grow and to physically support the regeneration process. They should 1) provide a three-dimensional architecture that supports a desired volume, shape, and mechanical strength; 2) have a high porosity and surface-to-volume ratio, with a well-interconnected open-pore structure to promote high seeding density and to embrace bioactive molecules; 3) be biocompatible; and 4) degrade at a controlled rate and pattern that allows sufficient support until tissue defects are fully regrown [37].

As mentioned above, scaffolds classically consist of random collagen sponges. However, extensive studies in scaffold engineering have been conducted in recent years, and scaffolds can be combined with cell- or gene-based approaches to serve as supportive carriers conducting a sustained release of bioactive factors, thereby inducing stimuli for tissue formation [9]. Bioactive molecules such as growth factors may also be encapsulated into nanoparticles and microparticles to aid in their sustained release from scaffolds. Other approaches include mimicking stem cell niches to regulate daughter cell proliferation, differentiation, and dispersion into surrounding tissue or attracting useful cells to a desired anatomic site [9, 38]. The feasibility to establish a three-dimensional polarity in scaffolding design constitutes an important advance in creating biomimetic scaffold surfaces that can be applied in gene

Table 2 Types and uses of biomaterial in periodontal engineering (36)

\begin{tabular}{lll}
\hline Biomaterial-free & Biomaterial-assisted & Biomaterial-based \\
\hline Cell suspension & Natural origin & Injectable (soft scaffolds) \\
Cell sheet engineering & Synthetic polymers & Solid biomaterials \\
$\begin{array}{c}\text { Cell pellets or } \\
\text { microtissues }\end{array}$ & Ceramics & Microencapsulation \\
& & Growth factor \\
& & ECM-composed
\end{tabular}


and cell therapy strategies [39]. Several other scaffold fabrication technologies have been used recently, including conventional prefabricated scaffolds such as particulate, solid form, and injectable scaffolds. Regardless of scaffold form, their purpose is the same, which is to influence the environment where they are implanted to promote a better outcome [40,41].

Conventional scaffolds are usually prefabricated from both natural and synthetic polymeric materials. Naturally derived scaffolds include autografts, allografts, and xenografts. Ceramics are another form of naturally derived scaffolds, most commonly used in bone regeneration and implant therapy [42]. Alloplasts and other polymers are synthetically engineered materials consisting of bioactive molecules that serve a purpose similar to that of natural scaffolds.

\section{Natural Polymers}

Most biomaterials of natural origin in use today are based on cross-linking or self-assembly properties, and they have an innate ability to interact with and mediate degradation by cells [9]. They form hydrophilic polymers with over $90 \%$ of water. Materials in this category include collagen, chitosan, dextran, alginate, Aloe vera, and fibrin.

Some interesting studies in periodontal engineering have been published within the last year where these materials have been used. A novel porcine acellular dermal matrix maintaining a 3D collagen framework has been tested both in vitro and in vivo. Together with hydroxyapatite, the construct has shown appropriate biodegradation patterns and favorable tissue compatibility [43]. Similarly, another new 3D scaffold made of collagen hydrogel, cross-linked to the ascorbatecopper ion system and injected into a collagen sponge, has demonstrated good biocompatibility and biodegradability 2 weeks after implantation in class II furcation defects (of $5 \mathrm{~mm}$ depth and $3 \mathrm{~mm}$ width) created in beagle dogs. Reconstruction of alveolar bone, cementum, and periodontal ligament was frequently observed as well just 4 weeks after surgery [44].

Platelet-rich fibrin's ability to promote cell proliferation, migration, and wound-healing is well-known and has been recently confirmed in periodontal tissues $[45,46]$. PRF is a biodegradable scaffold (replaced with dense collagen even after 2 weeks) [45] that stimulates the synthesis of many growth factors, including vascular endothelial growth factor (VEGF), thrombospondin 1 (TSP-1), connective tissue growth factor (CTGF), hepatocyte growth factor (HGF), and pro-collagen type I [46], but decreases alkaline phosphatase (ALP) activity and expression of bone sialoprotein (BSP) and osteocalcin $(\mathrm{OCN})$ while upregulating collagen I (Col-I) and cementum-derived protein 23 (CP-23) [47]. In vivo, in combination with PDLSC sheet fragments, it has been shown to promote more effective periodontal healing, characterized by regeneration of PDL-like tissues and reduction of ankylosis and inflammation [47].

Finally, another interesting natural polymer that is being studied is based on the Aloe vera extract known as acemannan [48]. This polysaccharide successfully stimulated both softand hard-tissue healing in class II furcation defects in mongrel dogs. However, little is known about this polymer, and further studies are needed.

\section{Ceramics}

The most used and studied ceramic material in the dental field is hydroxyapatite, which has been demonstrated to restore periodontal defects and to carry and deliver growth factors such as BMPs and fibroblast growth factor-2 (FGF2) [49]. Because increase of this material is inhibited by treatment with SB203580, a p38 inhibitor, and phosphorylation of p38, its ability to stimulate BMP-2 expression is dependent on the p38 MAP kinase pathway [50]. In the form of nanocrystals, it has some advantages over other materials. Compared to enamel matrix derivative (EMD), for example, nano-hydroxyapatite stimulates PDL cell proliferation and adhesion more efficiently, although cell migration is higher when using soluble EMD. These effects are mediated by alpha5beta1-mediated adhesion and focal adhesion kinase (FAK) activation [51]. Some studies have failed to prove an in vivo utility in periodontal regeneration when used alone [52]. Fortunately, nano-hydroxyapatite is a versatile material that can be combined with many polymers, either natural or synthetic, including chitosan [53], collagen [54], and gelatin [55], to improve the final results.

Another synthetic inorganic calcium phosphate-based material used as a delivery system is $\beta$-tricalcium phosphate. This material is primarily used in osseous defects around teeth or dental implants. Other composites in this group have begun to be used in periodontal engineering and are confirming its applicability as a stimulator of PDL cell proliferation and differentiation $[56,57]$. Their value for periodontal regeneration remains to be explored [9].

In this same category, bio-glasses or silicate-based crystals have similar properties and have been widely used in implant surfaces as biomimetic agents [42]. In periodontal regeneration, they may induce cementoblast proliferation [58] and osteogenic/cementogenic differentiation of PDL cells [59], and they are non-toxic, even in the form of nanoparticles [60]. They have been also used in combination with chitosan to create resorbable membranes that directly induce bone regeneration [61].

\section{Synthetic Polymers}

Synthetic polymers have been studied extensively in periodontal engineering [62]. They provide greater freedom for property modification, control of macrostructure, and 
degradation time, which can help to control the release mechanism and exposure duration of bioactive molecules [63, 64]. Such control provides the ability to maintain the therapeutic level of encoded proteins and to limit unwanted immune response and potential side effects [65].

The main representative agent in this category is the group of poly(lactic-co-glycolic acid)-based biomaterials. When configured as a microsphere, they have excellent properties for encapsulation of genes, antibiotics, and growth factors, as an occlusive membrane for guided tissue regeneration, and for cementum and complex tooth structure engineering. In addition to these promising applications, the use of nano-sized particles has attracted considerable attention [9]. Nano-sized particle-based scaffolds can provide a suitable environment for targeted cells and tissues in controlling the dynamic release of entrapped biologics. Periodontal therapy based on these systems, however, is only in the very early stages.

\section{Custom-Made and Functionalized Scaffolds}

Various novel delivery scaffolding systems are being extensively studied and are demonstrating superior capabilities to meet the challenges of current regeneration therapy. There are several techniques and technologies that have been developed and applied to fabrication of scaffold matrices. Only through further research and development in this area, along with cellbased and gene therapy, can tissue engineering continue to advance.

This concept relies upon computer-based scaffold design and fabrication [66]. This type of technology, image-based design, has been used in recent years to define virtual threedimensional models of anatomic geometry of the defect and to create a template for a scaffold on a global anatomic level [67•]. Furthermore, the scaffold can be designed to mimic the heterogeneous structures to be regenerated: variations in porous microstructures and scaffold surface topography, which will influence the modulus of elasticity, permeability, and cell orientation [39]. This hybrid scaffold concept has proven effective at establishing an adequate periodontal tissue interface that integrates the newly formed cementum, bone, and properly oriented PDL fibers in others studies as well [68].

One of the most important features of the periodontium is PDL fiber orientation from bone to cementum. A tissueengineering scaffold resembling the structure of the natural extracellular matrix by mimicking nanofibrous features can often facilitate tissue regeneration in bone, cartilage, enamel, dentin, and periodontium [69]. There are methods to create single- and multiple-channeled nanofibrous poly(L-lactic acid) scaffolds [70]. According to the authors of this study, the overall shape, the number and spatial arrangement of channels, the channel wall matrix architecture, the porosity and mechanical properties of the scaffolds are all tunable. The porous channel wall facilitates protein adsorption.

\section{Delivery of Molecules in Periodontal Engineering}

The delivery of different molecules, mainly growth factors [71], was the first approach in using a biological agent modifier for periodontal regeneration purposes. Because periodontal regeneration requires these molecules, it is very important to identify them to benefit periodontal engineering. Some are successfully being used in clinical studies [72]. They can be delivered either by recombinant products or gene therapy [64, 73]. Furthermore, gene therapy can be performed by directly delivering the infecting agent or by an indirect or cell-based delivery approach [9]. Table 3 shows various viral and non-viral gene therapy vectors used in tissue engineering (adapted from [9]).

Gene therapy can be defined as the treatment of disease or disorder by transferring genetic materials to introduce, suppress, or manipulate specific genes that direct an individual's own cells to produce a therapeutic agent [9]. Gene therapy has several advantages over traditional treatments, the first of which is greater sustainability than that of a single protein or compound application. Whereas the half-lives of pharmaceutical compounds or recombinant protein usually range from several hours to several days, viral vector genes can be expressed in vivo from weeks to years. Secondly, gene delivery reduces technical challenges associated with ex vivo protein expression and purification such as palmitoylation and glycosylation. Third, transient and controlled delivery of genetic sequences encoding a combinatorial group of regenerative factors could mimic the natural biologic healing response. And, fourth, coupled with tissue-engineering strategies, gene delivery in a spatially controlled and bioavailable fashion offers strong potential for three-dimensional tissue regeneration at the tooth-ligament-bone interface [9].

Various in vitro and ex vitro studies have suggested that PDGF (platelet-derived growth factor), FGF (fibroblast growth factor), IGF (insulin growth factor), BMP (bone morphogenic protein), and other growth factors are able to strongly stimulate periodontal regeneration, including both bone and cementum ([71].

\section{Platelet-Derived Growth Factor}

Platelet-derived growth factor (PDGF) is a member of a family of multifunctional polypeptide growth factors and is considered a critical switch to initiate tissue repair process. It is both a potent recruiter of and strong mitogenic factor for cells crucial to musculoskeletal tissue repair, including mesenchymal stem cells (MSCs), osteogenic cells, and tenocytes, and it also upregulates angiogenesis [74].

Recombinant human PDGF-BB in a synthetic scaffold matrix (beta-tricalcium phosphate) promotes long-term stable clinical and radiographic improvements for patients with localized periodontal defects [75]. Interestingly, a study of this 
Table 3 Viral and non-viral gene therapy vectors used in tissue engineering (9)

\begin{tabular}{|c|c|c|c|}
\hline Vector & Type & Advantages & Disadvantages \\
\hline \multirow[t]{2}{*}{ Retrovirus } & \multirow[t]{2}{*}{ Viral } & Non-immunogenic & Infects only dividing cells \\
\hline & & Constitutive transgene expression & Insertional mutagenesis \\
\hline \multirow[t]{3}{*}{ Lentivirus } & \multirow[t]{3}{*}{ Viral } & Infects dividing and non-dividing cells & Insertional mutagenesis \\
\hline & & Infects wide range of cell types & Potential pathogenicity \\
\hline & & Low immune response & $\begin{array}{l}\text { Complex large-scale } \\
\text { preparation }\end{array}$ \\
\hline \multirow[t]{2}{*}{ Adenovirus } & \multirow[t]{2}{*}{ Viral } & Infects dividing and non-dividing cells & Potential immunogenicity \\
\hline & & $\begin{array}{l}\text { Does not integrate into target cell } \\
\text { genome }\end{array}$ & Transient expression \\
\hline \multirow[t]{2}{*}{ Adeno-associated virus } & \multirow[t]{2}{*}{ Viral } & Infects dividing and non-dividing cells & $\begin{array}{l}\text { Difficult to produce at high } \\
\text { titers }\end{array}$ \\
\hline & & $\begin{array}{l}\text { Low immunogenicity } \\
\text { Non-pathogenic in human }\end{array}$ & Small transgenes \\
\hline Plasmid & Non-viral & $\begin{array}{l}\text { Non-immunogenic } \\
\text { Non-pathogenic }\end{array}$ & $\begin{array}{l}\text { Low transduction } \\
\text { efficiency }\end{array}$ \\
\hline DNA polymer complexes & Non-viral & $\begin{array}{l}\text { Infects dividing and non-dividing cells } \\
\text { Cell-specific targeting }\end{array}$ & $\begin{array}{l}\text { Low transduction } \\
\text { efficiency }\end{array}$ \\
\hline
\end{tabular}

growth factor showed a particularly greater effect in the lowerdose group $(0.3 \mathrm{mg} / \mathrm{mL})$. No special root preparation was made. A recent in vitro study demonstrated a higher rate of periodontal cell adhesion when using EDTA, PDGF, or a combination of both, compared to SRP (scaling and root-planing) or untreated groups. However, there was no significant difference between PDGF and PDGF+ EDTA groups [76]. Other dimers such as PDGF-AB have also been tested, but clinical application has not yet been approved [77].

There have been numerous gene therapy studies for periodontal regeneration using PDGF [78-82]. Most recently, analysis of the release of this growth factor by nano-sized calcium phosphate particles is showing promising results in terms of biocompatibility and efficient transfection into fibroblasts [83].

\section{FGF}

While it has not been used thus far in gene therapy, basic fibroblast growth factor, also known as FGF-2, may be of interest in the near future. In combination with beta-TCP, FGF-2 has proven efficacy in a root coverage study in beagle dogs [84] as well as in class III furcation defects [85].

Although FGF-2 induces proliferation of human periodontal ligament cells [86], it also decreases calcium accumulation and ALP activity, suggesting that it may inhibit terminal differentiation [87]. It has been recently shown to reduce the expression of SDF-1alpha (stromal cell-derived factor-1alpha) [88] via the FGFR1 [89]. SDF-1alpha has been reported as playing a crucial role in stem cell homing and recruitment to injured sites.

\section{Bone Morphogenetic Protein}

In dentistry, gene therapy with bone morphogenetic proteins (mainly 2 and 7) has been shown in vivo to stimulate not only cementum with Sharpey's fibers insertion, but also statistically significant quantities of alveolar bone [90, 91]. BMP-2 accelerates bone regeneration but is associated with limited cementum and periodontal ligament regeneration, local root resorption, and ankylosis when used as a recombinant protein. This negative effect in periodontal engineering could be overcome by the use of ex vivo BMP-2-engineered autologous MSCs [92]. Similarly, BMP-7 promotes proliferation, differentiation, and mineralized nodule formation, especially in cementoblasts [93] by inducing PCPE1 and BMP1 responsible for processing of type I collagen [94]. It also downregulates BMP-4, although it upregulates DMP-1, probably more through the IGF-II than the IGF-I pathway [93].

\section{Other Transcription Factors and Regulators}

In addition to growth factors, other critical transcription factors and regulators of osteogenesis that may be of great interest in periodontal tissue engineering and alveolar bone augmentation include RUNX2, osterix (Osx), and LIM domain mineralization protein (LMP) [9].

LMPs show potential in the modulation of periodontal progenitor cells (LMP1) [95]. Additionally, adenovirus delivery of LMP3 in hPDL cells can induce osteogenesis in vitro by significantly upregulating ALP (alkaline phosphatase), BSP (bone sialoprotein), and BMP2. Furthermore, when co-delivered with AdBMP7 in vivo, LMPS induce higher new bone formation [96]. 
Other mediators are being explored as well in the periodontal engineering arena. Specifically, our group is exploring the potential of a matricellular molecule named periostin in periodontal regeneration. Periostin, which is highly specific for the [97], is essential for PDL integrity and function during occlusal loading [12]. Furthermore, periostin is reduced by the proinflammatory cytokine TNF-alpha and the virulence factor $P$. gingivalis LPS in vitro, suggesting a potential role in the pathogenesis of periodontal disease [98]. Not surprisingly, in an animal model, higher inflammatory infiltrate and higher alveolar bone was correlated with lower levels of periostin in the PDL [99]. In this context, we investigated whether recombinant addition of periostin was able to restore the proliferation, migration capacities, and activation of survival signaling pathways of hPDL after being challenged by TNFalpha and $P$. gingivalis LPS. In this study, periostin significantly increased cell proliferation (by twofold), migration (especially at earlier time points and low dose), and activation of survival signaling pathway PI3K/AKT/mTOR (higher phosphorylation of AKT and PS6) under both nonchallenged and challenged conditions [100].

\section{Future Directions in Periodontal Engineering}

As discussed in this review, many different approaches and biologic agents are being studied in the area of periodontal engineering. The major challenge today remains the timely organization of the sequence of events that must happen with the healing area in order to promote the cells that are needed at each precise moment and without compromising normal cell function. New materials and signaling molecules - whether delivered by gene therapy or not - are therefore of great interest. Additional evidence and practice standardization are still needed in order to satisfy the regulatory requirements to apply these technologies in the clinical scenario. It is necessary to understand differences in the regenerative process between chronic periodontal pathology and other defects such as implant sites, extraction sockets, etc. The application of periodontal engineering, therefore, requires a thorough understanding of the homeostasis and pathogenesis of these defects.

\section{Conclusions}

Periodontal regeneration based on tissue engineering approaches has a solid background for clinical application in human periodontal defects. The cell-based, scaffold, and gene therapy methods interface and complement each other. However, some of these therapies are still at the preclinical level. In the near future, the success of periodontal regeneration will undoubtedly be conditioned on the ability to correctly diagnose clinical situations where these techniques can be predictably applied.

Acknowledgments The authors would like to thank Sarah Volk for her assistance in editing this manuscript. The authors receive funding support from the TALENTIA Scholarship Program and Research Group CTS \#583 (Junta de Andalucía, Spain) (MPM) and the NIH/NIDCR DE019872 (HR). The authors declare no financial interest in any of the products listed in this review.

\section{Compliance with Ethics Guidelines}

Conflict of Interest Dr. Miguel Padial-Molina received a grant from $\mathrm{NIH}$.

Dr. Hector F. Rios reported no potential conflicts of interest relevant to this article.

Human and Animal Rights and Informed Consent This article does not contain any studies with human or animal subjects performed by any of the authors.

\section{References}

Papers of particular interest, published recently, have been highlighted as:

- Of importance

-. Of major importance

1. Bartold PM, Narayanan AS. Molecular and cell biology of healthy and diseased periodontal tissues. Periodontology 2000. 2006;40: 29-49.

2. Eke PI, Dye BA, Wei L, Thornton-Evans GO, Genco RJ. Prevalence of periodontitis in adults in the United States: 2009 and 2010. J Dent Res. 2012;91:914-20.

3. Papapanou PN. The prevalence of periodontitis in the US: forget what you were told. J Dent Res. 2012;91:907-8.

4. Polimeni G, Xiropaidis AV, Wikesjo UM. Biology and principles of periodontal wound healing/regeneration. Periodontol. 2006;41: $30-47$.

5. Bartold PM, Shi S, Gronthos S. Stem cells and periodontal regeneration. Periodontology 2000. 2006;40:164-72.

6. Chen FM, An Y, Zhang R, Zhang M. New insights into and novel applications of release technology for periodontal reconstructive therapies. J Control Release. 2011;149:92-110.

7. Mudda JA, Bajaj M. Stem cell therapy: a challenge to periodontist. Indian J Dent Res. 2011;22:132-9.

8. Padial-Molina M, Marchesan JT, Taut AD, Jin Q, Giannobile WV, Rios HF. Methods to validate tooth-supporting regenerative therapies. Methods Mol Biol. 2012;887:135-48.

9. Rios HF, Lin Z, Oh B, Park CH, Giannobile WV. Cell- and genebased therapeutic strategies for periodontal regenerative medicine. J Periodontol. 2011;82:1223-37.

10. Taba Jr M, Jin Q, Sugai J, Giannobile WV. Current concepts in periodontal bioengineering. Orthod Craniofacial Res. 2005;8: 292-302.

11. Mao JJ, Giannobile WV, Helms JA, Hollister SJ, Krebsbach PH, Longaker MT, et al. Craniofacial tissue engineering by stem cells. J Dent Res. 2006;85:966-79.

12. Rios HF, Ma D, Xie Y, Giannobile WV, Bonewald LF, Conway SJ, et al. Periostin is essential for the integrity and 
function of the periodontal ligament during occlusal loading in mice. J Periodontol. 2008;79:1480-90.

13. Kawaguchi H, Hirachi A, Hasegawa N, Iwata T, Hamaguchi $H$, Shiba H, et al. Enhancement of periodontal tissue regeneration by transplantation of bone marrow mesenchymal stem cells. J Periodontol. 2004;75:1281-7.

14. Fournier BP, Ferre FC, Couty L, Lataillade JJ, Gourven M, Naveau A, et al. Multipotent progenitor cells in gingival connective tissue. Tissue Eng A. 2010;16:2891-9.

15. Marynka-Kalmani K, Treves S, Yafee M, Rachima H, Gafni Y, Cohen MA, et al. The lamina propria of adult human oral mucosa harbors a novel stem cell population. Stem Cells. 2010;28: 984-95.

16. Mitrano TI, Grob MS, Carrion F, Nova-Lamperti E, Luz PA, Fierro FS, et al. Culture and characterization of mesenchymal stem cells from human gingival tissue. J Periodontol. 2010;81: 917-25.

17. Su WR, Zhang QZ, Shi SH, Nguyen AL, Le AD. Human gingivaderived mesenchymal stromal cells attenuate contact hypersensitivity via prostaglandin E2-dependent mechanisms. Stem Cells. 2011;29:1849-60.

18. Tang L, Li N, Xie H, Jin Y. Characterization of mesenchymal stem cells from human normal and hyperplastic gingiva. J Cell Physiol. 2011;226:832-42.

19. Zhang Q, Shi S, Liu Y, Uyanne J, Shi Y, Le AD. Mesenchymal stem cells derived from human gingiva are capable of immunomodulatory functions and ameliorate inflammation-related tissue destruction in experimental colitis. J Immunol. 2009;183: 7787-98.

20. Xu X, Chen $\mathrm{C}$, Akiyama $\mathrm{K}$, Chai $\mathrm{Y}$, Le AD, Wang $\mathrm{Z}$ et al. Gingivae contain neural-crest- and mesoderm-derived mesenchymal stem cells. J Dent Res 2013.

21. Fawzy El-Sayed KM, Dorfer C, Fandrich F, Gieseler F, Moustafa $\mathrm{MH}$, Ungefroren $\mathrm{H}$. Adult mesenchymal stem cells explored in the dental field. Adv Biochem Eng Biotechnol 2012.

22.• Hynes K, Menicanin D, Han J, Marino V, Mrozik K, Gronthos S et al. Mesenchymal stem cells from ips cells facilitate periodontal regeneration. J Dent Res 2013. An alternative way to obtain mesenchymal stem cells (MSC) by controlled induction of induced pluripotent stem cells (iPSC) is presented in this article. Authors successfully applied this technique to significantly increase the amount of regeneration and newly formed mineralized tissue in periodontal defects. The most important aspect of this study is the description of a promising source of stem cells that might be permanently accesible and ready to use without the need of harvesting MSCs from their natural niches.

23. Park JC, Kim JC, Kim YT, Choi SH, Cho KS, Im GI, et al. Acquisition of human alveolar bone-derived stromal cells using minimally irrigated implant osteotomy: in vitro and in vivo evaluations. J Clin Periodontol. 2012;39:495-505.

24. Broccaioli E, Niada S, Rasperini G, Ferreira LM, Arrigoni E, Yenagi V, et al. Mesenchymal stem cells from Bichat's Fat Pad: in vitro comparison with adipose-derived stem cells from subcutaneous tissue. Biores Open Access. 2013;2:107-17.

25. Yu N, Oortgiesen DA, Bronckers AL, Yang F, Walboomers XF, Jansen JA. Enhanced periodontal tissue regeneration by periodontal cell implantation. J Clin Periodontol. 2013;40: 698-706.

26. Jung IH, Park JC, Kim JC, Jeon DW, Choi SH, Cho KS, et al. Novel application of human periodontal ligament stem cells and water-soluble chitin for collagen tissue regeneration: in vitro and in vivo investigations. Tissue Eng A. 2012;18: 643-53.

27. Seo BM, Miura M, Gronthos S, Bartold PM, Batouli S, Brahim J, et al. Investigation of multipotent postnatal stem cells from human periodontal ligament. Lancet. 2004;364:149-55.
28. Wang WJ, Zhao YM, Lin BC, Yang J, Ge LH. Identification of multipotent stem cells from adult dog periodontal ligament. Eur J Oral Sci. 2012;120:303-10.

29. Han J, Menicanin D, Marino V, Ge S, Mrozik K, Gronthos S, et al. Assessment of the regenerative potential of allogeneic periodontal ligament stem cells in a rodent periodontal defect model. J Periodontal Res 2013

30. Simsek SB, Keles GC, Baris S, Cetinkaya BO. Comparison of mesenchymal stem cells and autogenous cortical bone graft in the treatment of class II furcation defects in dogs. Clin Oral Investig. 2012;16:251-8.

31. Suaid FF, Ribeiro FV, Gomes TR, Silverio KG, Carvalho MD, Nociti Jr FH, et al. Autologous periodontal ligament cells in the treatment of class III furcation defects: a study in dogs. J Clin Periodontol. 2012;39:377-84.

32. Iwata $\mathrm{T}$, Washio $\mathrm{K}$, Yoshida $\mathrm{T}$, Ishikawa I, Ando T, Yamato M, et al. Cell sheet engineering and its application for periodontal regeneration. J Tissue Eng Regen Med 2013.

33.• Guo W, He Y, Tang X, Chen G, Shi H, Gong K, et al. Scaffold-free cell pellet transplantations can be applied to periodontal regeneration. Cell Transplant 2013. In this study, periodontal defects were regenerated by using scaffold-free multilayered cell pellets. If this approach is confirmed to be useful, the need of a scaffold might be reduced or eliminated, which obviously has important advantages.

34. Yang H, Gao LN, An Y, Hu CH, Jin F, Zhou J, et al. Comparison of mesenchymal stem cells derived from gingival tissue and periodontal ligament in different incubation conditions. Biomaterials. 2013;34:7033-47.

35. Fawzy El-Sayed KM, Paris S, Becker ST, Neuschl M, De Buhr W, Salzer S, et al. Periodontal regeneration employing gingival margin-derived stem/progenitor cells: an animal study. J Clin Periodontol. 2012;39:861-70.

36. Chen FM, Sun HH, Lu H, Yu Q. Stem cell-delivery therapeutics for periodontal tissue regeneration. Biomaterials. 2012;33: 6320-44.

37. Murphy WL, Mooney DJ. Controlled delivery of inductive proteins, plasmid DNA and cells from tissue engineering matrices. J Periodontal Res. 1999;34:413-9.

38. Discher DE, Mooney DJ, Zandstra PW. Growth factors, matrices, and forces combine and control stem cells. Science. 2009;324: 1673-7.

39. Park CH, Rios HF, Jin Q, Bland ME, Flanagan CL, Hollister SJ, et al. Biomimetic hybrid scaffolds for engineering human toothligament interfaces. Biomaterials. 2010;31:5945-52.

40. Chen W, Villa-Diaz LG, Sun Y, Weng S, Kim JK, Lam RH, et al. Nanotopography influences adhesion, spreading, and self-renewal of human embryonic stem cells. ACS Nano. 2012;6:4094-103.

41. Padial-Molina M, Galindo-Moreno P, Fernandez-Barbero JE, O'Valle F, Jodar-Reyes AB, Ortega-Vinuesa JL, et al. Role of wettability and nanoroughness on interactions between osteoblast and modified silicon surfaces. Acta Biomater. 2011;7:771-8.

42. Padial-Molina M, Galindo-Moreno P, Avila-Ortiz G. Biomimetic ceramics in implant dentistry. Minerva Biotechnol. 2009;21: 173-86.

43. Guo J, Chen H, Wang Y, Cao CB, Guan GQ. A novel porcine acellular dermal matrix scaffold used in periodontal regeneration. Int J Oral Sci. 2013;5:37-43.

44. Kosen Y, Miyaji H, Kato A, Sugaya T, Kawanami M. Application of collagen hydrogel/sponge scaffold facilitates periodontal wound healing in class II furcation defects in beagle dogs. J Periodontal Res. 2012;47:626-34.

45. Li Q, Pan S, Dangaria SJ, Gopinathan G, Kolokythas A, Chu S, et al. Platelet-rich fibrin promotes periodontal regeneration and enhances alveolar bone augmentation. Biomed Res Int. 2013;2013: 638043. 
46. Anitua E, Troya M, Orive G. An autologous platelet rich plasma stimulates periodontal ligament regeneration. J Periodontology 2013.

47. Zhao YH, Zhang M, Liu NX, Lv X, Zhang J, Chen FM, et al. The combined use of cell sheet fragments of periodontal ligament stem cells and platelet-rich fibrin granules for avulsed tooth reimplantation. Biomaterials. 2013;34:5506-20.

48. Chantarawaratit P, Sangvanich P, Banlunara W, Soontornvipart K, Thunyakitpisal P. Acemannan sponges stimulate alveolar bone, cementum and periodontal ligament regeneration in a canine class II furcation defect model. J Periodontal Res 2013.

49. Wikesjo UM, Lim WH, Thomson RC, Cook AD, Wozney JM, Hardwick WR. Periodontal repair in dogs: evaluation of a bioabsorbable space-providing macroporous membrane with recombinant human bone morphogenetic protein-2. J Periodontol. 2003;74:635-47.

50. Suto M, Nemoto E, Kanaya S, Suzuki R, Tsuchiya M, Shimauchi H. Nanohydroxyapatite increases BMP-2 expression via a p38 MAP kinase dependent pathway in periodontal ligament cells. Arch Oral Biol 2013.

51. Kasaj A, Willershausen B, Junker R, Stratul SI, Schmidt M. Human periodontal ligament fibroblasts stimulated by nanocrystalline hydroxyapatite paste or enamel matrix derivative. An in vitro assessment of PDL attachment, migration, and proliferation. Clin Oral Investig. 2012;16:745-54.

52. Lee JS, Park WY, Cha JK, Jung UW, Kim CS, Lee YK, et al. Periodontal tissue reaction to customized nano-hydroxyapatite block scaffold in one-wall intrabony defect: a histologic study in dogs. J Periodontal Implant Sci. 2012;42:50-8.

53. Ge S, Zhao N, Wang L, Yu M, Liu H, Song A, et al. Bone repair by periodontal ligament stem cellseeded nanohydroxyapatitechitosan scaffold. Int J Nanomedicine. 2012;7:5405-14.

54. Guo J, Wang Y, Cao C, Dziak R, Preston B, Guan G. Human periodontal ligament cells reaction on a novel hydroxyapatitecollagen scaffold. Dent Traumatol. 2013;29:103-9.

55. Rungsiyanont S, Dhanesuan N, Swasdison S, Kasugai S. Evaluation of biomimetic scaffold of gelatin-hydroxyapatite crosslink as a novel scaffold for tissue engineering: biocompatibility evaluation with human PDL fibroblasts, human mesenchymal stromal cells, and primary bone cells. J Biomater Appl. 2012;27:47-54.

56. Zhou Y, Wu C, Xiao Y. The stimulation of proliferation and differentiation of periodontal ligament cells by the ionic products from Ca7Si2P2O16 bioceramics. Acta Biomater. 2012;8:2307-16.

57. Zhang $\mathrm{Y}, \mathrm{Li} \mathrm{S}, \mathrm{Wu} \mathrm{C}$. The in vitro and in vivo cementogenesis of CaMgSi O bioceramic scaffolds. J Biomed Mater Res A 2013.

58. Carvalho SM, Oliveira AA, Jardim CA, Melo CB, Gomes DA, de Fatima Leite $\mathrm{M}$, et al. Characterization and induction of cementoblast cell proliferation by bioactive glass nanoparticles. J Tissue Eng Regen Med. 2012;6:813-21.

59. Wu C, Zhou Y, Lin C, Chang J, Xiao Y. Strontium-containing mesoporous bioactive glass scaffolds with improved osteogenic/ cementogenic differentiation of periodontal ligament cells for periodontal tissue engineering. Acta Biomater. 2012;8:3805-15.

60. Tavakoli M, Bateni E, Rismanchian M, Fathi M, Doostmohammadi A, Rabiei A, et al. Genotoxicity effects of nano bioactive glass and novabone bioglass on gingival fibroblasts using single cell gel electrophoresis (comet assay): an in vitro study. Dent Res J (Isfahan). 2012;9:314-20.

61. Mota J, Yu N, Caridade SG, Luz GM, Gomes ME, Reis RL, et al. Chitosan/bioactive glass nanoparticle composite membranes for periodontal regeneration. Acta Biomater. 2012;8:4173-80.

62. Liu X, Holzwarth JM, Ma PX. Functionalized synthetic biodegradable polymer scaffolds for tissue engineering. Macromol Biosci. 2012;12:911-9.
63. Jang JH, Houchin TL, Shea LD. Gene delivery from polymer scaffolds for tissue engineering. Expert Rev Med Devices. 2004;1:127-38.

64. Ramseier CA, Abramson ZR, Jin Q, Giannobile WV. Gene therapeutics for periodontal regenerative medicine. Dent Clin N Am. 2006;50:245-63. ix.

65. Ghali S, Dempsey MP, Jones DM, Grogan RH, Butler PE, Gurtner GC. Plastic surgical delivery systems for targeted gene therapy. Ann Plast Surg. 2008;60:323-32.

66. Smith LA, Ma PX. Computer-designed nano-fibrous scaffolds. Methods Mol Biol. 2012;868:125-34.

67. Park CH, Rios HF, Jin Q, Sugai JV, Padial-Molina M, Taut AD, et al. Tissue engineering bone-ligament complexes using fiberguiding scaffolds. Biomaterials. 2012;33:137-45. This study used a computer-designed approach to fabricate a bi-phasic scaffold and use it in vivo. The scaffold has specific areas of distinct fiberguiding zone to guide functionally-oriented ligamentous fiber regeneration in vivo. Cell transplantation using hybrid scaffolding constructs with guidance channels resulted in predictably oriented fiber architecture, greater control of tissue infiltration, and better organization of ligament interface than random scaffold architectures.

68. Vaquette C, Fan W, Xiao Y, Hamlet S, Hutmacher DW, Ivanovski S. A biphasic scaffold design combined with cell sheet technology for simultaneous regeneration of alveolar bone/periodontal ligament complex. Biomaterials. 2012;33: 5560-73.

69. Gupte MJ, Ma PX. Nanofibrous scaffolds for dental and craniofacial applications. J Dent Res. 2012;91:227-34

70. Sun C, Jin X, Holzwarth JM, Liu X, Hu J, Gupte MJ, et al. Development of channeled nanofibrous scaffolds for oriented tissue engineering. Macromol Biosci. 2012;12:761-9.

71. Sood S, Gupta S, Mahendra A. Gene therapy with growth factors for periodontal tissue engineering-a review. Med Oral Patol Oral Cir Bucal. 2012;17:e301-10.

72. Darby IB, Morris KH. A systematic review of the use of growth factors in human periodontal regeneration. J Periodontol. 2013;84: 465-76.

73. Ramseier CA, Rasperini G, Batia S, Giannobile WV. Advanced reconstructive technologies for periodontal tissue repair. Periodontol. 2012;59:185-202.

74. Friedlaender GE, Lin S, Solchaga LA, Snel LB, Lynch SE. The role of recombinant human platelet-derived growth factor-BB (rhPDGF-BB) in orthopaedic bone repair and regeneration. Curr Pharm Des. 2013;19:3384-90.

75. Nevins M, Kao RT, McGuire MK, McClain PK, Hinrichs JE, McAllister BS, et al. Platelet-derived growth factor promotes periodontal regeneration in localized osseous defects: 36-month extension results from a randomized, controlled, double-masked clinical trial. J Periodontol. 2013;84:456-64.

76. Belal MH, Watanabe H, Ichinose S, Ishikawa I. Effect of PDGF$\mathrm{BB}$ combined with EDTA gel on adhesion and proliferation to the root surface. Odontology. 2012;100:206-14.

77. Manoranjan SJ, Faizuddin M, Hemalatha M, Ranganath V. The effect of platelet derived growth factor- $\mathrm{AB}$ on periodontal ligament fibroblasts: an in vitro study. J Indian Soc Periodontol. 2012;16:49-53.

78. Giannobile WV, Lee CS, Tomala MP, Tejeda KM, Zhu Z. Plateletderived growth factor (PDGF) gene delivery for application in periodontal tissue engineering. J Periodontol. 2001;72:815-23.

79. Zhu Z, Lee CS, Tejeda KM, Giannobile WV. Gene transfer and expression of platelet-derived growth factors modulate periodontal cellular activity. J Dent Res. 2001;80:892-7.

80. Lin Z, Sugai JV, Jin Q, Chandler LA, Giannobile WV. Plateletderived growth factor-B gene delivery sustains gingival fibroblast signal transduction. J Periodontal Res. 2008;43:440-9. 
81. Anusaksathien O, Jin Q, Zhao M, Somerman MJ, Giannobile WV. Effect of sustained gene delivery of platelet-derived growth factor or its antagonist (PDGF-1308) on tissue-engineered cementum. J Periodontol. 2004;75:429-40.

82. Chang PC, Seol YJ, Cirelli JA, Pellegrini G, Jin Q, Franco LM, et al. PDGF-B gene therapy accelerates bone engineering and oral implant osseointegration. Gene Ther. 2010;17:95-104.

83. Elangovan S, Jain S, Tsai PC, Margolis HC, Amiji M. Nano-sized calcium phosphate particles for periodontal gene therapy. J Periodontol. 2013;84:117-25.

84. Ishii Y, Fujita T, Okubo N, Ota M, Yamada S, Saito A. Effect of basic fibroblast growth factor (FGF-2) in combination with beta tricalcium phosphate on root coverage in dog. Acta Odontol Scand. 2013;71:325-32.

85. Saito A, Saito E, Kuboki Y, Kimura M, Nakajima T, Yuge F, et al. Periodontal regeneration following application of basic fibroblast growth factor-2 in combination with beta tricalcium phosphate in class III furcation defects in dogs. Dent Mater J. 2013;32:256-62.

86. Hidaka T, Nagasawa T, Shirai K, Kado T, Furuichi Y. FGF-2 induces proliferation of human periodontal ligament cells and maintains differentiation potentials of STRO-1(+)/CD146(+) periodontal ligament cells. Arch Oral Biol. 2012;57:830-40.

87. Lee JH, Um S, Jang JH, Seo BM. Effects of VEGF and FGF-2 on proliferation and differentiation of human periodontal ligament stem cells. Cell Tissue Res. 2012;348:475-84.

88. Asakawa T, Chosa N, Yoshimura Y, Asakawa A, Tanaka M, Ishisaki A, et al. Fibroblast growth factor 2 inhibits the expression of stromal cell-derived factor 1alpha in periodontal ligament cells derived from human permanent teeth in vitro. Int J Mol Med. 2012;29:569-73.

89. Hasegawa T, Chosa N, Asakawa T, Yoshimura Y, Fujihara Y, Kitamura $\mathrm{T}$, et al. Differential effects of TGF-betal and FGF-2 on SDF-1alpha expression in human periodontal ligament cells derived from deciduous teeth in vitro. Int $\mathrm{J}$ Mol Med. 2012;30:35-40.

90. Chen YL, Chen PK, Jeng LB, Huang CS, Yang LC, Chung HY, et al. Periodontal regeneration using ex vivo autologous stem cells engineered to express the BMP-2 gene: an alternative to alveolaplasty. Gene Ther. 2008;15:1469-77.
91. Jin QM, Anusaksathien O, Webb SA, Rutherford RB, Giannobile WV. Gene therapy of bone morphogenetic protein for periodontal tissue engineering. J Periodontol. 2003;74:202-13.

92. Chung VH, Chen AY, Jeng LB, Kwan CC, Cheng SH, Chang SC. Engineered autologous bone marrow mesenchymal stem cells: alternative to cleft alveolar bone graft surgery. J Craniofac Surg. 2012;23:1558-63.

93. Bozic D, Grgurevic L, Erjavec I, Razdorov G, Brkljacic J, Orlic I, et al. Effect of bone morphogenetic protein-7 on gene expression of bone morphogenetic protein-4, dentin matrix protein-1, insulinlike growth factor-I and -II in cementoblasts in vitro. Coll Antropol. 2012;36:1265-71.

94. Bozic D, Grgurevic L, Erjavec I, Brkljacic J, Orlic I, Razdorov G, et al. The proteome and gene expression profile of cementoblastic cells treated by bone morphogenetic protein-7 in vitro. J Clin Periodontol. 2012;39:80-90.

95. Lin Z, Navarro VP, Kempeinen KM, Franco LM, Jin Q, Sugai JV, et al. LMP1 regulates periodontal ligament progenitor cell proliferation and differentiation. Bone. 2010;47:55-64.

96. Lin Z, Rios HF, Park CH, Taut AD, Jin Q, Sugai JV, et al. LIM domain protein-3 (LMP3) cooperates with BMP7 to promote tissue regeneration by ligament progenitor cells. Gene Ther. 2013;20:1-6.

97. Rios H, Koushik SV, Wang H, Wang J, Zhou HM, Lindsley A, et al. periostin null mice exhibit dwarfism, incisor enamel defects, and an early-onset periodontal disease-like phenotype. Mol Cell Biol. 2005;25:11131-44.

98. Padial-Molina M, Volk SL, Rodriguez JC, Marchesan JT, Galindo-Moreno P, Rios HF. Tumor necrosis factor-alpha and Porphyromonas gingivalis lipopolysaccharides decrease periostin in human periodontal ligament fibroblasts. J Periodontol. 2013;84:694-703.

99. Padial-Molina M, Volk SL, Taut AD, Giannobile WV, Rios HF. Periostin is down-regulated during periodontal inflammation. J Dent Res. 2012;91:1078-84.

100. Padial-Molina M, Volk SL, Rios HF. Periostin increases migration and proliferation of human periodontal ligament fibroblasts challenged by tumor necrosis factor -alpha and Porphyromonas gingivalis lipopolysaccharides. J Periodontal Res 2013. 